\title{
An Empirical Assessment of Mobile Service Performance Using Network Quality/Availability, Billing, Validity Period and Customer Care Services.
}

\author{
Adeyemo, F.S. \\ Department of Business Administration \\ Caleb University \\ Imota, Lagos State, Nigeria \\ E-mail: feliciaadeyemo@yahoo.com
}

\begin{abstract}
This paper examined customer satisfaction with Mobile service provision by analyzing primary data gathered using a research instrument designed for the purpose. Performance parameters of Network Quality/Availability, Billing, Validity Period and Customer Care Services were employed as variables to assess service provisions. With regards to factors that influence satisfaction, network quality demonstrated a strong influence on customer satisfaction. The implication of this finding is that network quality is the most significant of all the mobile services attributes and its quality strongly affect satisfaction. Billing, validity period and customer support showed weak influence on satisfaction. These results indicate that the evaluation of these factors without alignment is meaningless and have weak impact on satisfaction. The result also demonstrated that the combination of the mobile services attributes has strong influence on satisfaction.

Recommendations were made based on findings from the research
\end{abstract}

Keywords: FDI, Exchange rate, Economic growth, Development

Aims Research Journal Reference Format:

Adeyemo, F.S. (2018): An Empirical Assessment of Mobile Service Performance Using Network Quality/Availability, Billing, Validity Period and Customer Care Services. Advances in Multidisciplinary \& Scientific Research Journal. Vol. 4. No.3, Pp 73-87 Article DOI: dx.doi.org/10.22624/AIMS/V4N3P1

\section{INTRODUCTION}

Nigeria, a developing country, in 1992 introduced its first mobile phone services, through the joint venture between NITEL and DSL of Canada to form Mobile Telecommunications Service (MTS), (Ndukwe, 2005, pp 26). In January 2001, the regulatory body NCC, modernised and expanded the mobile telecommunications network and services by granting GSM license to three service providers; MTN Nigeria, Econet Wireless (now Vmobile), and the first national carrier, NITEL (initially MTS, privatised to form Mtel). In 2002, the second national carrier, Globacom was also granted license to commence operation. Since the launch of the GSM, the number of subscribers in Nigeria has greatly increased. Ndukwe (2005, pp 37-38, 40) reported that between 1998 and 2000, the number of mobile lines was 35,000 but grew to over 11 million as of March 2005, with a growth rate of more than a million lines annually since 2002 . This translated to an increase from the total density of 0.4 lines per 100 inhabitants in 1998 to 9.47 lines per 100 inhabitants currently. Additionally, this sector has attracted an investment of over US \$8 billion and has greatly increased the number of employed people directly (those working with the GSM companies) or indirectly (this includes various levels of dealerships, cell phone vendors, repair shops, suppliers of accessories, fixed and mobile call shops and street recharge card hawkers) (Hoff, 2006). The number of the employed people is reported to be over 300,000 Nigerians in 2005 (Ndukwe, 2005). Other benefits include easy, affordable and quick access to phone by different categories of the population, reduced frequency of travelling, etc (Bhave, 2003), and all these benefits contribute to the socio- economic development of the country. Based on the annual growth rate of the subscribers, and increasing teledensity, Nigeria is one of the fastest growing telecoms market in Africa (Hoff, 2006). Additionally, the population count of over 130 million people and GDP per capita and PPP valuation of US \$1,776 (estimated in 2005) (OECD, 2006) presents a massive growth potential for the mobile telecoms sector and the customer base is estimated to reach 23 million subscribers in 2007 and 32 million subscribers in 2009 (Hoff, 2006). This anticipated increase in the customer base will translate into better social and economic development, resulting from more financial investments from the service operators.

\section{RELATED WORKS}

The Global System of Mobile Communications (GSM) is a second-generation digital technology, which was originally developed in Europe and in less than ten years after the commercial launch, it developed into world's leading and fastest growing mobile standard (GSM Assoc., 2006). Lonergan et al. (2004) reported that at the beginning of 2004, there were over 1.3 billion mobile phone users worldwide and by 2007 , the demand for mobile services would have grown at an average annual rate of $9.1 \%$. 
The GSM Association estimates that the GSM technology is used by more than one in five people of the world's population, representing approximately $77 \%$ of the world's cellular market and is estimated to account for $73 \%$ of the world's digital market and $72 \%$ of the world's wireless market (GSM Assoc., 2006). This growth principally results from the establishment of new networks in developing countries rather than from an increase in mobile access lines in developed countries (Turel \& Serenko 2006). African countries are actively involved in the establishment of the mobile services and specifically, Nigeria is the focus of this study.

Studies conducted to explore factors affecting satisfaction, loyalty and retention in mobile telecommunications industry include: Gerpott et al. (2001) investigated customer satisfaction, loyalty and retention in the German mobile telecommunications among 684 respondents and reported that customer retention cannot be equated with customer loyalty and/or customer satisfaction, rather a two-stage causal link can be assumed in which customer satisfaction drives customer loyalty which in turn has impacts on customer retention. However, these three factors are important for superior economic success among telecommunication service providers. Kim et al. (2004) investigated the effects of customer satisfaction and switching barrier on customer loyalty among 350 respondents in Korea and reported that call quality, value-added services and customer support have significant impact on customer satisfaction. Thus, to maximize customer satisfaction, focus should be on service quality and customer-oriented services. Switching barrier on the other hand is affected by switching costs (e.g. loss cost, move-in cost, and interpersonal relationships) and was revealed to have an adjustment effect on customer satisfaction and customer loyalty. Serenko and Turel (2006) investigated customer satisfaction with mobiles services in Canada and reported that perceived quality and perceived value are the key factors influencing satisfaction with mobile services. Customer care is reported to be negatively related to customer satisfaction, which means that a more satisfied customer is less prone to complain. Hence, they concluded that customer satisfaction is the only single measure that better capture the range of services, prices and quality and moreso, this measure is an important performance indicator useful for both regulators and mobile service providers. In summary, these studies support the theory that highly satisfied customers stay longer, buy more, less sensitive to price increases from their providers or price decreases from competitors.

\subsection{Research Gaps}

Despite the economic and social benefits of the mobile telecommunications to Nigerian economy and market, unlike the developed countries, there is no marketing or management research attention to this sector. However, it is probable that the mobile operators conduct satisfaction surveys and other marketing research but contact with the mobile operators for any useful information yielded no response 1. This limitation affected this study in that there are currently no literature materials on customer satisfaction of the Nigerian mobile telecoms industry to consult. The majority of literature available (few in number) focuses on the study of the impact and development of the telecommunications, mobile telephony, communications, etc.

This lack of adequate research in the mobile telecoms sector may prevent it from acquiring knowledge useful for development. According to Serenko and Turel (2006), customer satisfaction measurement addresses both users and public interests and such studies can assist in economic and social development. Therefore, there is need to gain more understanding in the area of customer satisfaction. Jackson et al. (1996), Platow et al. (1997), and Homburg and Giering (2001) expressed that customer behaviours and attitudes are greatly influenced by demographic, situational, environmental and psychological factors and these factors can be used by companies and policy makers to develop strategies to meet different needs of the different customer segments. Hence, there is need to gain more understanding of the influence of these factors on customer satisfaction.

\section{RESEARCH DESIGN}

In order to investigate the objectives of this study and answer the hypotheses, survey technique or method was used to collect data and the questions were self constructed. The choices of questions for this investigation include questions on personal background; age- lowest range was 16-25 and highest was 66-75; gender- male/female; employment typeemployed (public, private and self), student and unemployed; and area of residence (Ikeja, Lagos Island, Mushin and Victoria Island).

The other questions were on variables used to assess mobile service performance; network quality/availability, billing, validity period and customer care services. The rating scale varied from "very satisfied" to "no opinion". Please see the Appendix 1 for full details of the questionnaire. The questionnaires were administered on the streets and the choice of this method of data collection was of high priority because the residents of Lagos State are mostly very busy people, who leave their homes for work or trade very early in the morning $(5.00 \mathrm{am})$ and return late (some people return as late between $10.00-11.00 \mathrm{pm}$ ). There will probably be little or no available time to attend to the questionnaires if dropped at their homes and failure of power supply (electricity) is very common at nights. Additionally, the street interviews presented better chance of having high representation of the sampling population, cheaper cost and rapid speed of data collection. 


\subsection{Population and Sampling Technique}

The population of the study compressed of all GSM mobile users in Lagos State. However, convenient sampling technique as employed to generate a sampling size of 400 in residential located in Lagos State, the commercial center, in the South West of Nigeria and these include:

i. Victoria Island (High income)

ii. Ikeja (Middle)

iii. Lagos Island (Middle-low)

iv. Mushin (Low)

Questionnaires were administered at four different locations. Since no list of customer was used, the residential locations were used as quota segment. These residential locations may relate to the level of income of the inhabitants and as well as to the level of use of the mobile services. The breakdown of these locations is based firstly on my experience of these areas and secondly, on the Wikipedia article (2006) on the history of Lagos State. Victoria Island is surrounded by several beaches (from the Atlantic Ocean) and has been choice of residence for top federal officers and diplomats since the colonial administration. The residences in this location are for federal parastals, diplomatic communities and rich individuals. Ikeja is the state capital and is the choice of residence for state parastals, corporate bodies, top state officers, civil officers, businessmen and averagely rich people. It is a choice of residence for civil officers, business people, etc. Lagos Island is the commercial center of the state. It is the choice of residence for corporate bodies (mostly headquarters), big markets, traders, business people, civil officers, etc, and has poorer housing structures.

Mushin is the choice of residence for traders, low ranked employees, etc. The location has problems of overcrowding, inadequate housing and poor sanitation. A total number of 400 people were interviewed for this study. This number is in accordance with the views of Dillman (2000) and Hill et al. (2003), who reported that a sample size of 100 and above is sufficient to present good concise research findings and also, provide good representation of the population or organization or any subject investigated. Selection is by convenience sampling (Non-probability sampling); interception of mobile users (questionnaires were handled out to every passerby and interested people waited to fill the forms) on streets in the central areas of the chosen locations on their way to work, lunch, school and shopping centers, etc. The points of data collection were changed within the chosen central locations to minimize bias. 100 respondents were administered the questionnaires in each location.

\subsection{Operationalisation and Measurement of Variables}

Table 3.1 Operational definitions of the content of the questionnaire

\begin{tabular}{|c|c|c|}
\hline Features/Contents & Operational definition & Measurement Scale \\
\hline Network availability & $\begin{array}{l}\text { Call quality as perceived by customers and this } \\
\text { include: } \\
\text { Call clarity when calling and receiving } \\
\text { Coverage }\end{array}$ & \multirow[t]{5}{*}{$\begin{array}{l}\text { All the variables were measure } \\
\text { with five point Likert Scale }\end{array}$} \\
\hline Billing & $\begin{array}{l}\text { The cost of refilling credit (pricing): } \\
\text { Variety of refill card } \\
\text { Affordability of the refill card } \\
\text { Freedom of choosing refill cards } \\
\text { Speed of refilling }\end{array}$ & \\
\hline Validity period & $\begin{array}{l}\text { The period in which you can make calls and or } \\
\text { receive calls after every refill }\end{array}$ & \\
\hline Customer Care & $\begin{array}{l}\text { Customer support and complaint management } \\
\text { systems: } \\
\text { Promptness (ability to get attendant quickly) } \\
\text { Attitude (response of the attendant) } \\
\text { Competence (ability to provide a solution) }\end{array}$ & \\
\hline Customer satisfaction & $\begin{array}{l}\text { an experience-based assessment made by the } \\
\text { customer of how far his own expectations about the } \\
\text { individual characteristics or the overall functionality of } \\
\text { the services obtained from the provider have been } \\
\text { fulfilled }\end{array}$ & \\
\hline
\end{tabular}

Source: Literature Review, 2018. 


\subsection{Research Instrument}

A questionnaire was the instrument used in this study to collect data. The questionnaire employed the typical form of fixed-response alternative questions that require the respondent to select from a predetermined set of answers to every question. According to Malhotra and Birks (2003, pp. 224), this survey approach is the most common method of primary data collection in marketing research and the advantages are simple administration and data consistency. The survey questionnaires were administered on the streets (mode of data collection): the questionnaires were filled out mostly by the people themselves or through the interviewers for few people who could not understand English. Malhotra and Birks (2003) showed in their evaluation of comparative survey techniques that street interviews have high flexibility of data collection, high degree of diversity of questions due to interaction and high response rate, moderate sample control, moderate quantity of data, moderate to high great potential to probe respondents, moderate to high great potential to build rapport, moderate to high speed and cost of data collection. These qualities were responsible for the choice of this survey technique for this study. The questionnaires employed the Likert non-comparative scaling technique. It is a widely used rating scale which requires the respondents to indicate a degree of agreement or disagreement with each of a series of statements or questions (Albaum, 1997).

This rating scale is easy to construct and administer and respondents readily understand how to use the scale (Malhotra and Birks, 2003, pp. 305). The Likert scale used in this study is odd numbered (as proposed by Spagna, 1984); balanced (the number of favourable and unfavourable categories is equal). This view is proposed by Watson (1992), who reported the balanced state helps to obtain an objective data; has non-forced choices "no opinion" to improve the accuracy of the data (as proposed by Hasnich, 1992); and 5-scaled categories which conforms to the traditional guidelines reported by Aaker (1997). He proposed that the categories scale should be between 5 and 9 .

The questionnaire contains two sections; A and B. Section A has questions on demography (age, gender, employment and location) and the section B includes questions on mobile provider, rating of service quality (network availability, billing and validity period), customer care service (promptness, attitude and competence), and the rating of the service performance. In all, the questionnaire contains eight questions and the answers are "very satisfied", "satisfied", "dissatisfied", "very dissatisfied" and "no opinion". The questionnaire was constructed entirely in English. Please see table 3.1 for the operation definition for the content of the questionnaires and appendix 1 for a copy of the questionnaire.

\subsection{Source of Data}

The study uses primary source

\subsection{Method of Data Analysis}

The Statistical Package for Social Sciences (SPSS) 12.0 will be used to analyze the data collected. The descriptive statistics (frequencies statistics) will be applied to assess the level of customer satisfaction while the relationship between the mobile services attributes, specific demographic variables and customer satisfaction will be analyzed with the linear regression model. The major limitation that will emerge in this study will be the inability to use random sampling. Another limitation of the study is the restriction of the geographical coverage to users of GSM in Lagos State. 


\section{DATA PRESENTATION AND ANALYSES}

The purpose of this quantitative study was to assess service quality and customer satisfaction with telecommunication operators in Nigeria. This chapter therefore presents the descriptive statistics (frequency statistics) of the independent variables (demographics).

\subsection{Presentation of Data}

Table 4.1: Demographic Characteristics of the Respondents

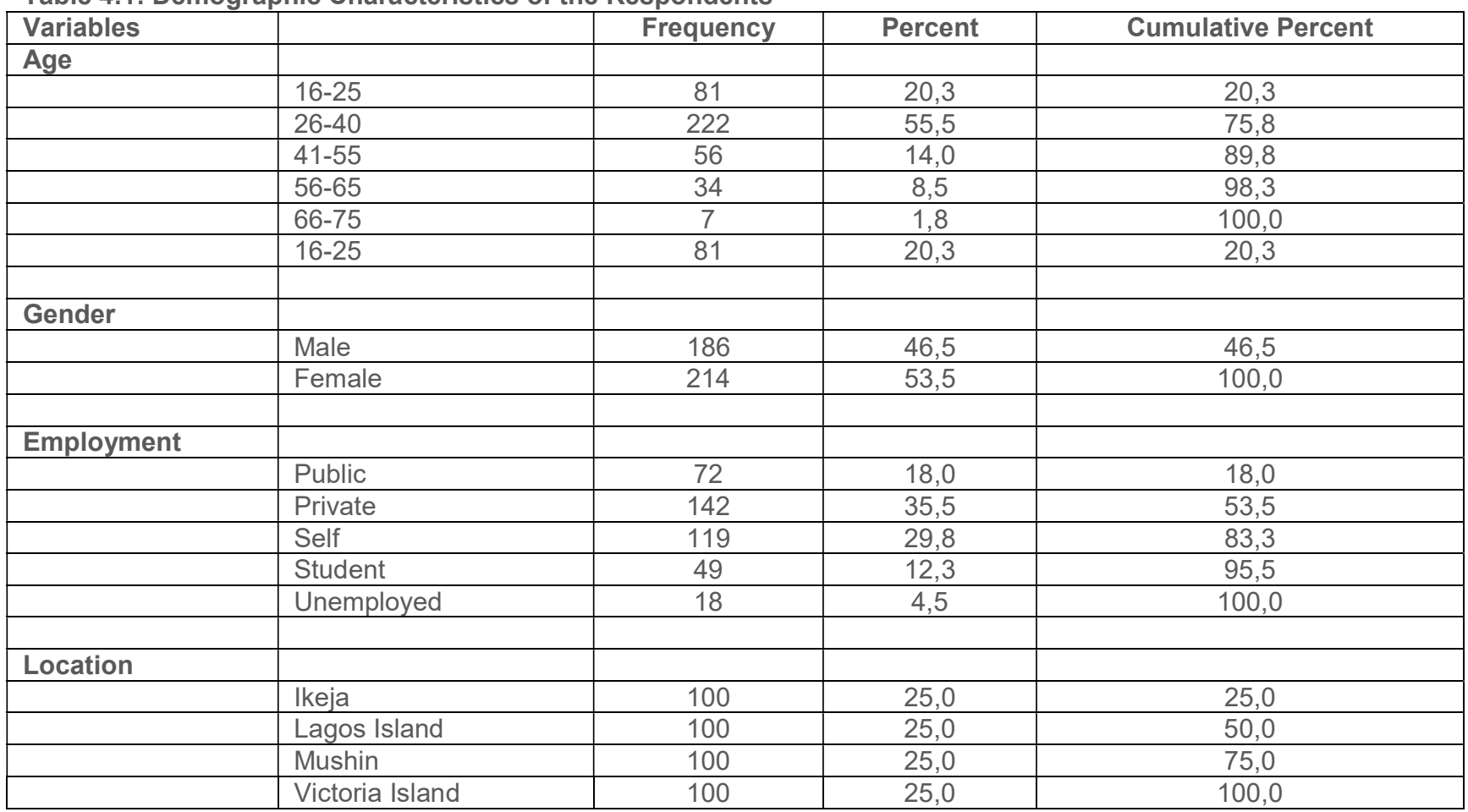

Source: Field Survey, 2018.

\subsection{Analysis of the Research Questions}

\subsubsection{Customer Satisfaction}

The dependent variable (customer satisfaction) was analyzed with the descriptive statistics (frequency distribution). Table 4.2 presents the result of the analyzed overall customer satisfaction.

\begin{tabular}{|l|l|l|l|l|}
\hline Satisfaction & & Frequency & Percent & Cumulative Percent \\
\hline & Very satisfied & 20 & 5,0 & 5,0 \\
\hline & Satisfied & 228 & 57,0 & 62,0 \\
\hline & Dissatisfied & 137 & 34,3 & 96,3 \\
\hline & Very dissatisfied & 8 & 2,0 & 98,3 \\
\hline & No opinion & 7 & 1,5 & 100,0 \\
\hline
\end{tabular}

Source: Field Survey, 2018. 


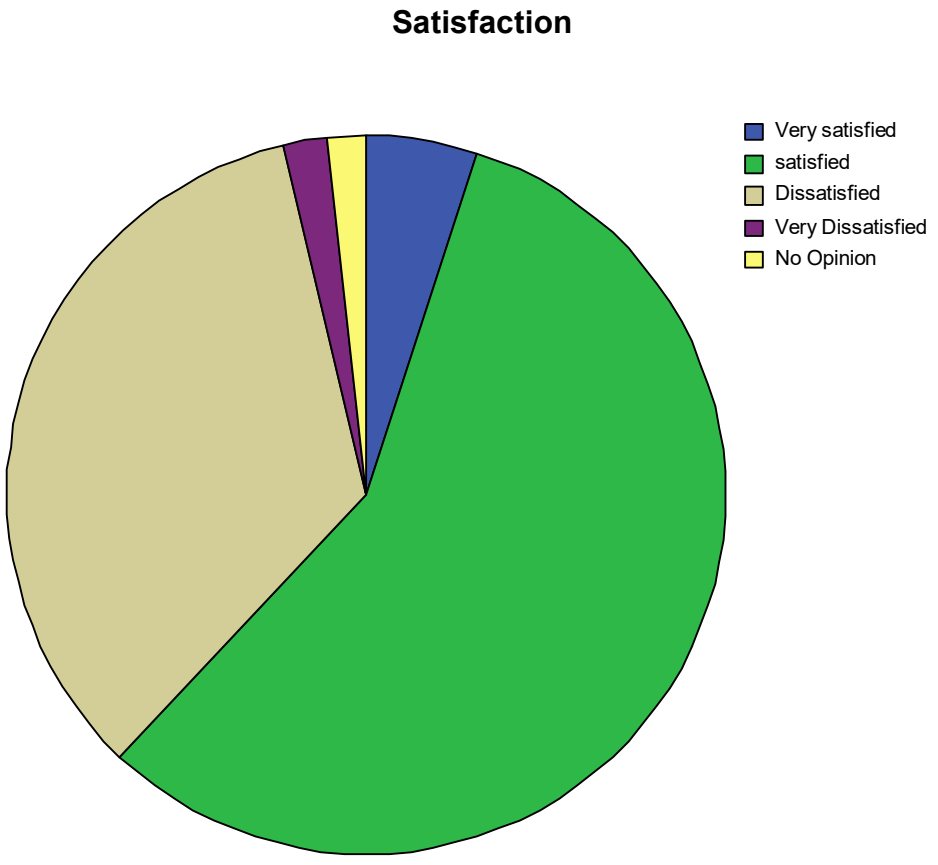

The piechart represents the outcome of the analysis of the Nigerian

customer satisfaction with the mobile telecoms services (frequency distribution in percentage)

Fig. 4.1: Pie-chart representation of customer satisfaction

This result demonstrates that $57 \%$ of the respondents are satisfied, and $5 \%$ very satisfied with the mobile telecoms services in Nigeria and hence, supports $\mathrm{H}_{1}$. Although this score is slightly above average, it is a fairly good assessment for a mobile telecoms sector that is barely 5 years old. The interpretation of this result could be that Nigerian customers are truly satisfied with the mobile service performance and its impact. In line with the adopted definition, this result showed that customers are satisfied with their experiences of use of the mobile services (services meet expectation).

This satisfaction measure could also result from lack of viable competitor that the customers can compare services with and/or could be due to the fact that customers are kind of new to satisfaction measurement and may not be able to express their perceptions well. Thus, there is need for routine customer satisfaction measurement to better capture customers perceptions. However, this result supports the previous studies conducted on customer satisfaction of mobile operators in Germany with $28 \%$ of the respondents satisfied (Gerpott et al., 2001), the United States - 65\% of the respondents were satisfied (ACSI, 2004), and in Canada $-54.67 \%$ of the respondents were satisfied (Turel and Serenko, 2006). 


\subsubsection{Customer Satisfaction among the Demographic Groups}

The demographic variables were analysed against customer satisfaction using the cross tab of the descriptive analysis to show assessments of customer satisfaction among various categories of the demographic variables. Table 4.3 presents the outcome of the analysis.

Table 4.3: Cross tabulation

\begin{tabular}{|c|c|c|c|c|c|c|c|c|}
\hline Variables & & $\begin{array}{c}\text { Very } \\
\text { satisfied }\end{array}$ & Satisfied & Dissatisfied & $\begin{array}{c}\text { Very } \\
\text { dissatisfied }\end{array}$ & $\begin{array}{c}\text { No } \\
\text { opinion }\end{array}$ & Total & $\begin{array}{c}\text { Satisfaction } \\
(\%)\end{array}$ \\
\hline \multirow[t]{5}{*}{ Age } & $16-25$ & 0 & 46 & 28 & 0 & 7 & 81 & 56.8 \\
\hline & $26-40$ & 4 & 144 & 66 & 8 & 0 & 222 & 66.7 \\
\hline & $41-55$ & 16 & 12 & 28 & 0 & 0 & 56 & 50 \\
\hline & $56-65$ & 0 & 19 & 15 & 0 & 0 & 34 & 55.8 \\
\hline & $66-75$ & 0 & 7 & 0 & 0 & 0 & 7 & 100 \\
\hline \multirow[t]{2}{*}{ Gender } & Male & 4 & 123 & 44 & 8 & 7 & 186 & 68.3 \\
\hline & Female & 16 & 105 & 93 & 0 & 0 & 214 & 56.5 \\
\hline \multirow[t]{5}{*}{ Employment } & Public & 0 & 65 & 7 & 0 & 0 & 72 & 90.3 \\
\hline & Private & 16 & 46 & 65 & 8 & 7 & 142 & 43.7 \\
\hline & Self & 0 & 62 & 57 & 0 & 0 & 119 & 52.1 \\
\hline & Student & 4 & 37 & 8 & 0 & 0 & 49 & 83.7 \\
\hline & Unemployed & 0 & 18 & 0 & 0 & 0 & 18 & 100 \\
\hline \multirow[t]{5}{*}{ Location } & Ikeja & 0 & 63 & 37 & 0 & 0 & 100 & 63 \\
\hline & Lagos island & 4 & 60 & 32 & 4 & 0 & 100 & 64 \\
\hline & Mushin & 7 & 60 & 33 & 0 & 0 & 100 & 67 \\
\hline & $\begin{array}{l}\text { Victoria } \\
\text { island }\end{array}$ & 9 & 45 & 35 & 4 & 7 & 100 & 54 \\
\hline & & & & & & & & \\
\hline
\end{tabular}

Source: Field Survey, 2018.

Table 4.4 presents the result of the assessment of customer satisfaction in 2 categories of demographic variables.

\begin{tabular}{|l|l|c|}
\hline Variables & & Satisfaction (Mean) (\%) \\
\hline Age & Young & 61.8 \\
\hline & Old & 68.6 \\
\hline Gender & & 68.3 \\
\hline & Male & 56.5 \\
\hline Employment & Female & 72 \\
\hline & & 91.9 \\
\hline & Employed & \\
\hline Location & Unemployed & 58.5 \\
\hline & & 65.5 \\
\hline
\end{tabular}

Note: Young - those under 40, Old - those over 40; Employed - those in public, private and self employment,

Unemployed - students, unemployed (those seeking jobs, retired, etc); High income - Ikeja and Victoria Island dwellers

status, Low income - Lagos Island and Mushin dwellers status.

Source: Field Survey, 2018.

This result demonstrates that customer satisfaction level differs among the various demographic variables and hence, supports $\mathrm{H}_{2}$. Within the age groups, the old people are more satisfied than the young people. The low satisfaction of the young people could result from the fact that they are more demanding as a result of their greater familiarity with mobile technologies and higher tendency to complain than the old people. This result supports the findings of Bryant et al., 1996, which reported that satisfaction increases with age and major increase seen within the age of 55 and above; the younger age groups are less satisfied than older age groups across all products and services industries (VanAmburg, 2004); Venn and Fone (2005) reported that higher satisfaction is significantly related with increasing age; and Turel and Serenko (2006), in their study of mobile telecoms revealed that there is lower satisfaction level among young adults. 
Within the gender groups, this result revealed that male customers are more satisfied than the female. The higher satisfaction reported by the male customers may imply that they are well satisfied with the impact of the service and/or the mobile telecoms boost their functional activities (businesses, sales, etc), while for the female customers, their low satisfaction could be due to less or no personal interaction with sales process (mobile subscription is through vendors and not directly from the operators, unlike the fixed telecoms) or less influence of mobile telecoms on their relational activities. This result is in contrast with the findings of Bryant et al. (1996), who revealed that the female customers are more satisfied than the male customers across all industries; Venn and Fone (2005) revealed that higher satisfaction is positively related to female gender.

The result also indicates that the unemployed customers are more satisfied that the employed ones. Employment relates to education. Unemployment results from both lack of jobs for qualified people and lack of education. The higher satisfaction of the unemployed customers could be that they are truly satisfied with the services irrespective of their status or their perception is a result of their level of education. This study did not examine the influence of education on satisfaction and future studies could investigate this. Additionally, this result confirms the findings of Venn and Fone (2005), which reported higher satisfaction level among unemployed customers.

Accordingly, customers living within the low-income areas are more satisfied than those in the high-income areas. Highincome areas dwellers have greater tendency to be more familiar with information technologies and be more demanding and these factors could be responsible for the low satisfaction obtained in the high-income areas. This result confirms the findings of Bryant et al. (1996) which reported that the higher the income, the lower the satisfaction.

\subsection{Analyses of the Research Objectives}

\subsubsection{Determinants and Customers Satisfaction}

To explore the relationship between mobile services attributes and customer satisfaction, the linear regression model was applied. $R$ and $R^{2}$ values range between 0 and 1 with larger values indicating stronger relationship. The following subsections present the results. The Model summary table reports the strength of the relationship between the model and the dependent variable. "R" value indicates the strength of relationship with larger values indicating stronger relationship and

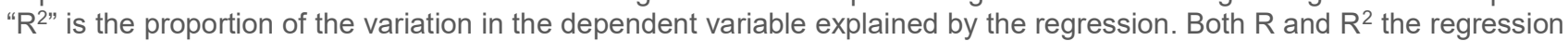
procedure values range from 0 to 1 .

Table 4.5 presents the result of the relationship between network quality and satisfaction.

Table 4.5: The Relationship between Network Quality and Satisfaction

Model Summary

\begin{tabular}{|l|l|l|l|l|}
\hline & & & & \\
\hline 1 & $\mathrm{R}$ & R Square & Adjusted R Square & Std. Error of the Estimate \\
\hline
\end{tabular}

a. Predictors: (Constant), Network

Source: Field Survey, 2018.

This result indicates that there is a strong relationship between network quality and customer satisfaction and thus, supports $\mathrm{H}_{3}$. The implication of this result is that network quality of the telephone services is the most significant of all the mobile service attributes in Nigeria. Secondly, the result means that the customers perception of network quality strongly influence their perception of mobile operators and their satisfaction level. From my experience of Lagos State, network quality is very good, especially in the major cities such as the locations used in this study but some times, climatic conditions such as rainfall, strong wind, etc affect the call quality. Network quality involves call clarity and coverage and mobile operators should focus on improving network quality to create higher satisfaction. Please see appendix 2 for full statistical result.

Table 4.6 presents the result of the relationship between billing and satisfaction

Table 4.6: The Relationship between Billing and Satisfaction

\begin{tabular}{|l|l|l|l|l|}
\hline & & & \\
Model & $\mathrm{R}$ & R Square & Adjusted R Square & Std. Error of the Estimate \\
\hline 1 & $.444(\mathrm{a})$ & .197 & .195 & .62340 \\
\hline
\end{tabular}

a. Predictors: (Constant), Billing

Source: Field Survey, 2018. 
This result demonstrates that there is a weak relationship between billing and customer satisfaction and thus, contradicts $\mathrm{H}_{4}$. This finding means that billing (pricing structure) has negligible significance out of mobile services attributes in Nigeria. Secondly, the price paid to access the mobile services has little influence on customer satisfaction level. Thirdly, the finding could indicate that billing is meaningless without aligning it with other mobile services attributes. Thus, mobile operators need to provide reasonable pricing that are aligned with good mobile services attributes to maximise satisfaction and routine satisfaction assessment should be conducted. Lastly, this result may probably be due to the fact that the mobile technology is new in the country and rapidly gaining acceptance. Please see appendix 3 for full statistical result.

Table 4.8 presents the result of the relationship between overall customer care and satisfaction.

Table 4.8: Relationship between overall customer care service and satisfaction Model Summary

\begin{tabular}{|l|l|l|l|l|}
\hline Model & R & R Square & Adjusted R Square & Std. Error of the Estimate \\
\hline 1 & $.396(a)$ & .157 & .155 & .63887 \\
\hline
\end{tabular}

a. Predictors: (Constant), overall customer care

Source: Field Survey, 2018.

This result demonstrates that there is a weak relationship between overall customer care and customer satisfaction and thus, contradicts $\mathrm{H}_{6}$. The implication of this result is that customer care service has negligible significance out of mobile services attributes in Nigeria. Secondly, customer care service has little influence on Nigerian customers satisfaction level. Thirdly, the result could indicate that customer care service is meaningless without aligning it with other mobile services attributes. Thus, mobile operators need to provide reasonable validity period that are aligned with good mobile services attributes to maximise satisfaction and routine satisfaction evaluation should be done. Lastly, this result may probably be due to the fact that the mobile technology is relatively new in the country.

From my experience, at times it takes about an hour of holding your call to successfully make a query or lodge a complain and it is therefore interesting to observe that customer care service has weak influence on satisfaction. Customer care service whether good or bad is demonstrated by this study to have weak influence on satisfaction but its influence on other customer attitudes (such as word of mouth) is not investigated. Future study can conduct this investigation. Please see appendix 5 for full statistical result.

Table 4.9 presents the result between the combined mobile services attributes and satisfaction

Table 4.9: Relationship between overall customer care, billing, network quality and customer satisfaction

\begin{tabular}{|l|l|l|l|l|}
\hline & \multicolumn{3}{l|}{ Model Summary } & \\
Model & $\mathrm{R}$ & R Square & Adjusted R Square & Std. Error of the Estimate \\
\hline 1 & $.676(\mathrm{a})$ & .457 & .452 & .51469 \\
\hline
\end{tabular}

a. Predictors: (Constant), overall customer care, billing, and network quality.

Source: Field Survey, 2018.

This result demonstrates that the interaction of the mobile services attributes have a strong relationship with customer satisfaction and thus, supports. The interpretation of this finding is that the aligned mobile services attributes is significant to the assessment of the customer satisfaction with mobile services. Therefore, customer satisfaction with Nigerian mobile services is a function of the assessment of network quality and customer care service. Thus, mobile operators should focus on improving mobile services attributes to heighten customer satisfaction.

This strong relationship outcome supports the findings of Booz, Allen and Hamilton (1995); Danaher and Rust (1996); Bolton (1998); Gerpott (1998); and Wilfert (1999), which reported that the aforementioned attributes are key drivers of the customer value of the mobile services and key factors affecting customer satisfaction. Please see appendix 6 for full statistical result. 


\subsubsection{Analyses of Research Hypotheses}

\section{Relationship between Demographic Variables And Customer Satisfaction}

To explore the relationship between demographic variables and customer satisfaction, the linear regression model was applied. $R$ and $R^{2}$ values range between 0 and 1 with larger values indicating stronger relationship. The following subsections present the results.

Table 4.10 presents the result of the relationship between age and customer satisfaction

Table 4.10: Relationship between age and customer satisfaction Model Summary

\begin{tabular}{|c|l|l|l|l|}
\hline Model & $\mathrm{R}$ & $\begin{array}{l}\mathrm{R} \\
\text { Square }\end{array}$ & $\begin{array}{l}\text { Adjusted } \\
\text { R Square }\end{array}$ & Std. Error of the Estimate \\
\hline 1 & $.126(\mathrm{a})$ & .016 & .013 & .69027 \\
\hline
\end{tabular}

a. Predictors: (Constant), Age

Source: Field Survey, 2018.

This result demonstrates that there is a weak relationship between age and customer satisfaction and hence, contradicts $\mathrm{H}_{8}$. The interpretation of the result is that age has a negligible impact on customer perception of how well the mobile services meet needs and expectations. This result could probable be due to the fact the mobile telecoms industry is still growing and/or is too early to establish such relationship because the study is new to Nigerian customers. Thus, there is need for routine assessment to investigate this relationship.

This result supports the findings of Jessie and Sheila (2001) and Oyewole (2001) which reported that age has a minimal influence on satisfaction and contradicts the findings of Palvia and Palvia (1999), Lightner (2003) and Turel and Serenko (2006) which reported that age is a significant determinant of satisfaction with information technology and mobile telecoms industry. Please see appendix 7 for full statistical result.

Table 4.11 presents the result of the relationship between gender and customer satisfaction

Table 4.11: Relationship between gender and customer satisfaction

\begin{tabular}{|l|l|l|l|l|}
\hline & & & Adjusted \\
Rodel & $\mathrm{R}$ & R Square & R Sqare & Std. Error of the Estimate \\
\hline 1 & $.039(\mathrm{a})$ & .002 & -.001 & .69531 \\
\hline
\end{tabular}

a. Predictors: (Constant), Gender

Source: Field Survey, 2018.

This result demonstrates that there is a weak relationship between gender and customer satisfaction and hence, contradicts $\mathrm{H}_{9}$. The rejection of the hypothesis means that gender has negligible influence on customer perception of mobile services performance. This result could also probable be due to the fact the mobile telecoms industry is still growing and/or is too early to establish such relationship because the study is new to Nigerian customers. Thus, there is need for routine assessment to investigate this relationship.

This result supports the findings of Jessie and Sheila (2001) which reported that gender has a minimal influence on satisfaction and contradicts the findings of Oyewole (2001) which reported that gender has significant influence on satisfaction. Please see appendix 8 for full statistical result.

Table 4.12 presents the result of the relationship between location and customer satisfaction

Table 4.12: Relationship between location and customer satisfaction Model Summary

\begin{tabular}{|c|c|c|c|c|}
\hline Model & $\mathrm{R}$ & R Square & $\begin{array}{l}\text { Adjusted } \\
\text { R Square }\end{array}$ & Std. Error of the Estimate \\
\hline 1 & $.151(a)$ & .023 & .015 & .68964 \\
\hline
\end{tabular}


a. Predictors: (Constant), Victoria Island, Lagos Island, Ikeja, Mushin Source: Field Survey, 2018.

This result demonstrates that there is a weak relationship between location and customer satisfaction and hence, contradicts $\mathrm{H}_{10}$. The implication of this finding is that location has negligible influence on how customers perceive service performance. This result could as well be due to the fact the mobile telecoms industry is still growing and/or is too early to establish such relationship because the study is new to Nigerian customers. Thus, there is need for routine assessment to investigate this relationship. This result supports the findings of Jessie and Sheila (2001) which reported that location has a minimal influence on satisfaction. Please see appendix 9 for full statistical result.

Table 4.13 presents the result of the relationship between employment and customer satisfaction

Table 4.13: Relationship between employment and customer satisfaction Model Summary

\begin{tabular}{|l|l|l|l|l|}
\hline Model & R & R Square & $\begin{array}{l}\text { Adjusted } \\
\text { R Square }\end{array}$ & Std. Error of the Estimate \\
\hline 1 & $.332(\mathrm{a})$ & .110 & .099 & .65971 \\
\hline
\end{tabular}

a. Predictors: (Constant), Unemployed, Student, Public, Self, and Private employment

Source: Field Survey, 2018.

This result demonstrates that there is a weak relationship between employment type and customer satisfaction and hence, contradicts $\mathrm{H}_{11}$. This result means that employment status has negligible impact on how customers evaluate service performance. This result could as well be due to the fact the mobile telecoms industry is still growing and/or is too early to establish such relationship because the study is new to Nigerian customers. Thus, there is need for routine assessment to investigate this relationship.

This result also contradicts the findings of Oyewole (2001) and Ahmad and Kamal (2002) which reported that occupation has a significant influence on satisfaction. Please see appendix 10 for full statistical result.

Table 4.14 presents the result of the relationship between age, gender and customer satisfaction

Table 4.14: Relationship between age and gender and customer satisfaction Model Summary

\begin{tabular}{|l|l|l|l|l|}
\hline & & & Adjusted \\
Rodel & $\mathrm{R}$ & R Square & Std. Error of the Estimate \\
\hline 1 & $.141(\mathrm{a})$ & .020 & .015 & .68973 \\
\hline
\end{tabular}

a. Predictors: (Constant), Gender, Age

Source: Field Survey, 2018.

This result demonstrates that the interaction between age and gender variables have a weak influence on customer satisfaction and thus, contradicts $\mathrm{H}_{12}$. The interpretation of this finding indicates that age aligned with gender has negligible effect on customer perception of service performance and like the previous results, the result could probable be due to the growing state of the mobile industry and/or the new study, which maybe too early to establish this relationship. However, routine investigations are needed to investigate this relationship. Please see appendix 11 for full statistical result.

Table 4.15 presents the result of the relationship between age, location and customer satisfaction

Table 4.15: Relationship between age, location and customer satisfaction Model Summary

\begin{tabular}{|l|l|l|l|l|}
\hline Model & R & R Square & Adjusted R Square & Std. Error of the Estimate \\
\hline 1 & $.190(\mathrm{a})$ & .036 & .026 & .68580 \\
\hline
\end{tabular}

Predictors: (Constant), Victoria Island, Age, Lagos Island, Ikeja, Mushin

Source: Field Survey, 2018.

This result indicates that the interaction of age and location variables have a weak influence on customer satisfaction and 
hence, contradicts $\mathrm{H}_{13}$. This result contradiction means that age aligned with location has negligible impact on customer assessment of service performance, and like the previous results, the result could probable be due to the growing state of the mobile industry and/or the new study, which maybe too early to establish this relationship.

Hence, routine evaluation should be conducted to investigate this relationship. Please see appendix 12 for full statistical result.

Table 4.16 presents the result of relationship between age, employment and satisfaction

Table 4.16: Relationship between age, employment and satisfaction Model Summary

\begin{tabular}{|l|l|l|l|l|}
\hline Model & R & R Square & Adjusted R Square & Std. Error of the Estimate \\
\hline 1 & $.375(\mathrm{a})$ & .140 & .127 & .64921 \\
\hline
\end{tabular}

a. Predictors: (Constant), Unemployed, Student, Public, Self, Private employment and Age

Source: Field Survey, 2018.

This result demonstrates that the interaction of the age and employment variables have a weak influence on customer satisfaction and contradicts $\mathrm{H}_{14}$. This finding means that age aligned with employment status has negligible effect on customer perception of how well mobile services satisfy needs, and like the previous results, the result could probable be due to the growing state of the mobile industry and/or the new study, which maybe too early to establish this relationship. Thus, routine assessment should be conducted to investigate this relationship. Please see appendix 13 for full statistical result.

Table 4.17 presents the result of the relationship between gender, location and satisfaction

Table 4.17: Relationship between gender, location and satisfaction Model Summary

\begin{tabular}{|l|l|l|l|l|}
\hline Model & R & R Square & $\begin{array}{l}\text { Adjusted } \\
\text { R Square }\end{array}$ & Std. Error of the Estimate \\
\hline 1 & $.157(\mathrm{a})$ & .025 & .015 & .68984 \\
\hline
\end{tabular}

a. Predictors: (Constant), Victoria Island, Lagos Island, Ikeja, Mushin and Gender

Source: Field Survey, 2018.

The result demonstrates that the interaction of gender and location variables have a weak influence on customer satisfaction and contradicts $\mathrm{H}_{15}$. The interpretation of this result is that gender aligned with location has negligible impact on customer ratings of service performance, and like the previous results, the result could probable be due to the growing state of the mobile industry and/or the new study, which maybe too early to establish this relationship. Please see appendix 14 for full statistical result.

Table 4.18 presents the result of the relationship between gender, employment and satisfaction

Table 4.18: Relationship between gender, employment and satisfaction Model Summary

\begin{tabular}{|l|l|l|l|l|}
\hline Model & R & R Square & $\begin{array}{l}\text { Adjusted } \\
\text { R Square }\end{array}$ & Std. Error of the Estimate \\
\hline 1 & $.366(a)$ & .134 & .121 & .65171 \\
\hline
\end{tabular}

a. Predictors: (Constant), Unemployed, Student, Self, Public, Private employment and Gender

Source: Field Survey, 2018.

The result demonstrates that the interaction of gender and employment variables have a weak influence on customer satisfaction and contradicts $\mathrm{H}_{16}$. This finding means that gender aligned with employment status has negligible influence on how customers perceive service performance. Like the previous results, this result could as well be due to the fact the mobile telecoms industry is still growing and/or is too early to establish such relationship because the study is new to Nigerian customers. Thus, there is need for routine assessment to investigate this relationship. Please see appendix 15 for full statistical result. 
Table 4.19 presents the result of the relationship between location, employment and satisfaction

Table 4.19: Relationship between Location, Employment and Satisfaction Model Summary

\begin{tabular}{|l|l|l|l|l|}
\hline Model & R & R Square & $\begin{array}{l}\text { Adjusted } \\
\text { R Square }\end{array}$ & Std. Error of the Estimate \\
\hline 1 & $.377(\mathrm{a})$ & .142 & .124 & .65029 \\
\hline
\end{tabular}

a. Predictors: (Constant), Victoria Island, Lagos Island, Ikeja, Mushin, Unemployed, Student, Public, Self, Private employment

Source: Field Survey, 2018.

The result demonstrates that the interaction of location and employment variables have a weak influence on customer satisfaction and contradicts $\mathrm{H}_{17}$. The implication of this result is that location aligned with employment status has negligible influence on customer ratings of service performance. Like the other previous results, this result could as well be due to the fact the mobile telecoms industry is still growing and/or is too early to establish such relationship because the study is new to Nigerian customers. Thus, there is need for routine assessment to investigate this relationship. Please see appendix 16 for full statistical result.

Table 4.20 presents the result of the relationship between all demographic variables and satisfaction

Table 4.20: Relationship between all demographic variables and satisfaction Model Summary

\begin{tabular}{|l|l|l|l|l|}
\hline Model & R & R Square & $\begin{array}{l}\text { Adjusted } \\
\text { R Square }\end{array}$ & Std. Error of the Estimate \\
\hline 1 & $.443(\mathrm{a})$ & .196 & .175 & .63112 \\
\hline
\end{tabular}

a. Predictors: (Constant), Unemployed, Student, Self, Public, Private, Victoria Island, Lagos Island, Ikeja, Mushin,

Gender, Age

Source: Field Survey, 2018.

The result demonstrates that the interaction of age, gender, location and employment variables have a weak influence on customer satisfaction and contradicts $\mathrm{H}_{18}$. This finding indicates that the alignment of age, gender, location and employment factors have negligible impact on how Nigerian customers perceive service performance. Like the previous results, this result could as well be due to the fact the mobile telecoms industry is still growing and/or is too early to establish such relationship because the study is new to Nigerian customers. Thus, there is need for routine assessment to investigate this relationship. Please see appendix 17 for full statistical result.

\section{DISCUSSION OF FINDINGS, CONCLUSION AND RECCOMENDATIONS}

\subsection{Discussion of Findings}

With regards to factors that influence satisfaction, network quality demonstrated a strong influence on customer satisfaction. The implication of this finding is that network quality is the most significant of all the mobile services attributes and its quality strongly affect satisfaction. Billing, validity period and customer support showed weak influence on satisfaction. These results indicate that the evaluation of these factors without alignment is meaningless and have weak impact on satisfaction. The result also demonstrated that the combination of the mobile services attributes has strong influence on satisfaction. Thus, to increase customer satisfaction, mobile operators should focus on improving mobile services attributes by investing in equipment to enhance call quality and coverage, offer reasonable pricing and price discounts, offer reasonable validity period and enhance customer care through routine personnel training and provision of better customer-friendly equipment.

With regards to influence of demographic variables on satisfaction, the result showed that the individual variables (age, gender, employment status and location) and their combination have weak influence on satisfaction. These results mean that customers perceptions of how well the mobile services meet their needs are not affected by these specific variables. However, since the results showed different customer satisfaction levels among the various demographic groups, mobile operators can strive to better understand these market segments and adopt marketing strategies to better satisfy their different needs. 
With regards to customer satisfaction measurement, the results demonstrated that customers are satisfied with the performance of the Nigerian mobile telecoms industry. The interpretation of this result could be that Nigerian customers are truly satisfied with the service performance (satisfied with experience of the mobile services use) or their satisfaction results from lack of competing services or it could be that the customers are new to satisfaction measurement and may not be able to express their perceptions well. The result also demonstrated that customer satisfaction level differs among the specific demographic groups. Within the age groups, the older customers were more satisfied than younger ones. The low satisfaction of the young customers could be due to greater familiarity with mobile technologies and are more demanding. The male customers showed more satisfaction than the female counterpart. The high satisfaction of the male customers could be due to the impact of the services on their functional activities. The unemployed customers demonstrated more satisfaction than the employed ones and the higher satisfaction of the unemployed group could be due to true satisfaction or low knowledge of mobile technologies. Lastly, the low-income areas showed more satisfaction than the high-income areas.

\subsection{Conclusion}

Broadly, this study concludes that mobile operators should not just rely on profit margins as a good indicator of business performance, they should also develop strategies that better capture customers perceptions of their service offerings and these strategies can complement the internal perceptions of service offering. Customer satisfaction strategy helps companies to compare their performance against customer standards, compare customer standards against internal process and identify opportunities for improvement.

\subsection{Recommendations}

From practical policy, this study recommends that mobile operators can strive to better understand Nigeria market segments and adopt marketing strategies to better satisfy their different needs. It recommends that mobile operators should focus on improving mobile services attributes by investing in equipment to enhance call quality and coverage, offer reasonable pricing and price discounts, offer reasonable validity period and enhance customer care through routine personnel training and provision of better customer-friendly equipment. Mobile operators need to strive to maximize customer satisfaction which in turn can influence the extent of loyalty and retention.

From academic, this study suggests that there is need for cooperation between academic bodies and mobile operators so as to achieve better customer-oriented investigations. Future studies can further investigate the factors that affect satisfaction and loyalty (such as level of education, word of mouth, life cycles and usage pattern of customers, switching barriers, etc).

\subsection{Suggestions for Further Studies}

The sample size was relatively small and respondent coverage was limited to Four various locations in Lagos state and generalisation to a wider population of mobile telecommunication providers ought to be undertaken with great care. The study recommends further studies to increase sample size and consider the entire city of Lagos for a thorough assessment /evaluation of the subject matter. 


\section{BIBLIOGRAPHY}

1. Bhave, A., 2002- "Customer satisfaction measurement", Quality and Productivity Journal, Symphony Technologies Pvt Ltd, Erendavane, India.

2. Bolton, R.N. (1998) - A dynamic model of the duration of the customer's relationship with a continuous service provider: the role of satisfaction", Marketing Science, Vol. 17 No. 1, pp. 45-65.

3. Booz Allen, \& Hamilton (1995)- Mobilfunk. Frankfurt/M.: IMK.

4. Danaher, P. J., \& Rust, R. T. (1996) - Indirect financial benefits from service quality. Quality Management Journal, 3(2), pp.63-75.

5. Gerpott, T. J. (1998)- Wettbewerbsstrategien im Telekommunikationsmarkt (3rd ed.). Stuttgart: SchafferPoeschel.

6. Gerpott, T.J., Rams, W., and Schindler, A., (2001) - "Customer retention, loyalty, and satisfaction in the German mobile telecommunications market, Telecommunications Policy, Vol. 25 No. 4, pp.249 - 269.

7. GSM Association (2006) - www.gsmworld.com

8. Homburg, C., \& Bruhn, M. (1998). Kundenbindungsmanagement - Eine EinfuK hrung in die theoretischen and praktischen Problemstellungen. In M. Bruhn, \& C. Homburg (Eds.), Handbuch Kundenbindungsmanagement (pp. 3\}35).Wiesbaden: Gabler.

9. Jackson, L.A., Sullivan, L.A., Harnish, R. and Hodge, C.N. (1996)-"Achieving positive social identity: social mobility, social creativity, and permeability of group boundaries", Journal of Personality and Social Psychology, Vol. 70, pp. 241-54.

10. Kim, H. (2000) - The churn analysis and determinants of customer loyalty in Korean mobile phone. Korean Information Society Review, 2000, 1-18.

11. Lee, J., Lee, J., \& Freick, L. (2001) - The impact of switching costs on the customer satisfaction-loyalty link: Mobile phone service in France. Journal of Services Marketing, 15(1), 35-

12. Ndukwe, Ernest (2005) - Country experience in telecom market reforms in Nigeria. CEO, Nigerian Communication Commission, July 2005. www.ncc.gov.ng.

13. Platow, M. J., Harley, K., Hunter, J. and Banning, P. (1997) - "Interpreting in-group-favoring allocations in the minimal group paradigm", British Journal of Social Psychology, Vol. 36, pp. 107-17.

14. Szyperski, N., \& Loebbecke, C. (1999). Telekommunikationsmanagement (TKM) als betriebswirtschaftliche Spezialdisziplin. Die Betriebswirtschaft, 59, 481\} 495.

15. Turel, O. and Serenko, A. (2006) - Satisfaction with mobile services in Canada: An empirical investigation, Telecommunications Policy 30 (2006), pp.314-331, 2006.

16. Wilfert, A. (1999)- Der Wettbewerb auf dem Mobilfunkmarkt in Deutschland. In D. Fink, \& A. Wilfert (Eds.), Handbuch Telekommunikation und Wirtschaft (pp. 187\}202). MuK nchen: Vahlen. 